CASE REPORT

\title{
Isolated conjunctival lymphoma metastasis from previous low grade non-Hodgkin's lymphoma
}

\author{
P Cackett, M Bower, J Stebbing
}

Postgrad Med J 2005;81:el (http://www.postgradmedi.com/cgi/content/full/81/953/el). doi: 10.1136/pgmj.2004.026344

Ocular involvement of systemic non-Hodgkin's lymphoma is rare. This report describes the unusual occurrence of a biopsy confirmed low grade lymphoma recurring in the conjunctiva, three years after initial diagnosis of systemic disease. The tumour was surgically resected and the patient remains disease free four years later. After the diagnosis of lymphoma, long term follow up is advised as recurrences in unusual sites can occur.

t has been reported that up to $1 \%$ of all patients with nonHodgkin's lymphoma (NHL) have evidence of orbital involvement including adnexae, extra-ocular muscles, eyelids, and/or the lacrimal glands. ${ }^{1}$ These tumours are often small, remain localised, and may therefore be asymptomatic. While primary conjunctival lymphoid tumours are well described $^{2}{ }^{3}$ and may even affect both eyes, ${ }^{4}$ conjunctival metastasis from systemic spread seems to be rare. ${ }^{1}$ In addition, most cases of lymphoma involving tissues in and around the eye are low or intermediate grade and, considered to be of mucosal associated lymphoid tissue origin. ${ }^{156}$

We describe a 47 year old man with no pre-disposing factors who presented with a large conjunctival lesion three years after systemic chemotherapy for a low grade follicular B-cell NHL, originally confined to his cervical nodes. Excision biopsy of the conjunctival lesion showed recurrence of his lymphoma. Presentations such as this are rare and show the importance of close follow up and biopsy of any suspicious lesions in anyone with a previous history of cancer. While differential diagnoses in this case are extensive, early diagnosis may prevent or disclose further systemic spread.

\section{CASE REPORT}

A 47 year old man presented with a three year history of enlarged lymph nodes on both the right and the left sides of the neck. There was no significant medical history and he had no systemic symptoms. On examination several enlarged cervical lymph nodes were palpable bilaterally with no evidence of hepatomegaly or splenomegaly.

He subsequently underwent excisional biopsy of the right neck nodes. The tissue had a nodular pattern comprising a mixture of small lymphocytes including prominent centrocytes and occasional centroblasts. Most of the node architecture was abnormal and there was significant extranodal infiltration. Immunohistochemistry showed that the tumour cells were positive for the B cell marker CD20, and the follicular lymphoma markers $\mathrm{CD} 10, \mathrm{Bcl}-2$ and Bcl6 with no reactivity to the $\mathrm{T}$ cell markers $\mathrm{CD} 5$ or $\mathrm{CD} 3$. These appearances were consistent with those of a follicular B cell NHL. Bone marrow aspirate and trephine were normal and computed tomography (CT) showed no evidence of disease elsewhere. The lymphoma was therefore staged as $2 \mathrm{a}$ disease.

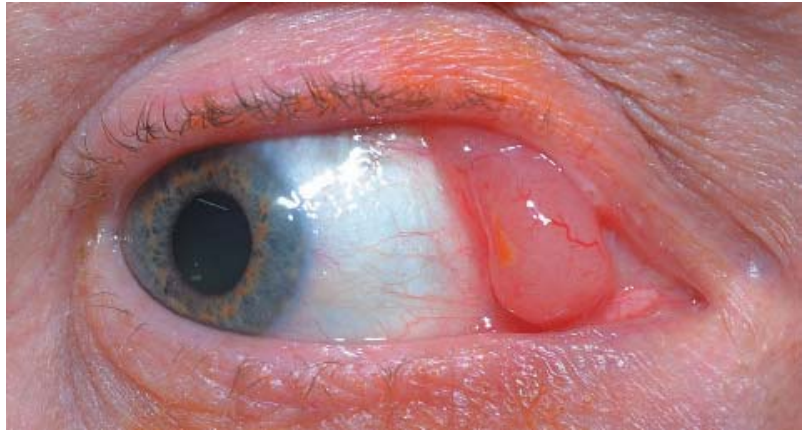

Figure 1 The conjunctival lymphoma metastasis in the patient's right eye.

The patient underwent chemotherapy with chlorambucil and subsequent bilateral field radiotherapy to the neck. Initially a good clinical response was seen however, at 18 months after initial presentation a right axillary lymphadenopathy was noted. Biopsy of the lesion showed recurrence and CT showed no evidence of any other disease. This stage 3 lymphoma was treated with a further course of chlorambucil and a complete response was observed.

Three years after initial presentation he developed a large pink fleshy lesion supero-medially in the conjunctiva of the right eye (fig 1). This lesion was subsequently excised and pathological appearances of the lesion again were similar to those of the cervical node with a diagnosis of metastatic follicular NHL grade 3. Repeat CT showed no evidence of any new disease elsewhere and review at six months showed no evidence of recurrence of the conjunctival lesion; follow up radiotherapy was therefore not felt to be necessary. The patient remains free of recurrent disease at four years after initial presentation.

\section{DISCUSSION}

Late relapse of lymphomas at unusual sites have been described previously and the orbit but not the conjunctiva seems to be a major secondary site for such events. ${ }^{12}$ Primary conjunctival lymphomas often appear to masquerade for many months as conjunctivitis and a number of misdiagnoses have been reported..$^{3-5}$ Differential of the most common and important conjunctival lesions includes includes pterygium, pingecula, papilloma, kaposi's sarcoma, lymphoid tumours, limbal dermoid, dermolipoma, lymphangioma, granuloma, amelanotic melanoma, amyloid, and sebaceous cell carcinoma. Referral to an ophthalmologist is mandatory for ocular assessment, and neoplastic diagnoses should lead to systemic investigation including CT scans.

Abbreviations: NHL, non-Hodgkins's lymphoma; CT, computed tomography 
Aspiration of the conjunctival surface can be performed using a tuberculin syringe without a needle and in one feasibility study, the cytological diagnosis accurately correlated with the histological diagnosis. ${ }^{6}$ However, the main use of cytology in this setting appears to direct an area where biopsy should be performed.

Patients with lymphoma recurrence require adequate staging although in this case his further disease appeared confined to his conjunctiva. Radiotherapy with moderate doses of 25-35 Gy is the primary treatment modality and the main side effects are cataracts and keratitis. ${ }^{2}$ For mucosal associated lymphoid tissue tumours, the initial response to radiotherapy predicts probability of later recurrence ${ }^{8}$ and this is likely to be true for other lymphomas although studies have not been undertaken. New techniques being investigated include intravitreal chemotherapy, cryotherapy, or the injection of interferons. A particularly novel therapy recently described has entailed transplantation with amniotic membranes to treat conjunctival tumours including lymphoma, ${ }^{9}$ the lack of a blood supply preventing rejection in this case.

The patient had no evidence of immunosuppression, often considered an important factor in the development of such tumours. ${ }^{10-12}$ Infection with the HIV has been shown to increase the incidence of a number of tumours including NHL. ${ }^{13-15}$ At the Chelsea and Westminster Hospital, London, over 9000 HIV positive patients have been followed up since the 1980s and this has included over 200 cases of AIDS related NHL. ${ }^{16}$ No conjuctival metastases have been observed and only one patient had a primary conjunctival lymphoma.

Conjunctival lymphoma should however be considered in the differential of chronic conjunctivitis and biopsy specimens should always be referred to a pathologist who specialises in lymphoma. Further appropriate management results in 10 year survival rates of over $90 \%$.

\section{Authors' affiliation}

P Cackett, Princess Alexandra Eye Pavilion, Edinburgh, UK

M Bower, J Stebbing, The Departments of Oncology and HIV Medicine, Chelsea and Westminster Hospital, London, UK
Correspondence to: Dr P Cackett, Princess Alexandra Eye Pavilion, Chalmers Street, Edinburgh EH3 9HA, UK; pete@pdcackett.demon. co.uk

Submitted 1 July 2004

Accepted 9 August 2004

\section{REFERENCES}

1 Ishikawa D, Nakayama I, Azumi A, et al. [A case of orbital lymphoproliferative lesion diagnosed as malignant lymphoma after recurring 11 years later]. Nippon Ganka Gakkai Zasshi 1999;103:821-5.

2 Stafford SL, Kozelsky TF, Garrity JA, et al. Orbital lymphoma: radiotherapy outcome and complications. Radiother Oncol 2001;59:139-44.

3 Lee DH, Sohn HW, Park SH, et al. Bilateral conjunctival mucosa-associated lymphoid tissue lymphoma misdiagnosed as allergic conjunctivitis. Cornea 2001;20:427-9.

4 Akpek EK, Polcharoen W, Chan R, et al. Ocular surface neoplasia masquerading as chronic blepharoconjunctivitis. Cornea 1999;18:282-8.

5 Akpek EK, Polcharoen W, Ferry JA, et al. Conjunctival lymphoma masquerading as chronic conjunctivitis. Ophthalmology 1999; 106:757-60.

6 Grossniklaus HE, Stulting RD, Gansler T, et al. Aspiration cytology of the conjunctival surface. Acta Cytol 2003;47:239-46.

7 Regueiro CA, Valcarcel FJ, Romero J, et al. Treatment of conjunctival lymphomas by beta-ray brachytherapy using a strontium-90-yttrium-90 applicator. Clin Oncol (R Coll Radiol) 2002;14:459-63.

8 Uno T, Isobe K, Shikama N, et al. Radiotherapy for extranodal, marginal zone, B-cell lymphoma of mucosa-associated lymphoid tissue originating in the ocular adnexa: a multiinstitutional, retrospective review of 50 patients. Cancer 2003;98:865-71.

9 Chen $\mathrm{Z}$, Yan J, Yang $\mathrm{H}$, et al. Amniotic membrane transplantation for conjunctival tumor. Yan Ke Xue Bao 2003;19:165-7, 145.

10 Beral V, Newton R. Overview of the epidemiology of immunodeficiencyassociated cancers. J Natl Cancer Inst Monogr 1998;2:1-6.

11 Santos J, Palacios R, Ruiz J, et al. Unusual malignant tumours in patients with HIV infection. Int J STD AIDS 2002;13:674-6.

12 Kramer M, Lynn W, Lightman S. HIV/AIDS and the eye. Hosp Med 2003;64:421-4.

13 Thirlwell C, Sarker D, Stebbing J, et al. Acquired immunodeficiency syndrome-related lymphoma in the era of highly active antiretroviral therapy. Clin Lymphoma 2003;4:86-92.

14 Stebbing J, Bower M. What can oncologists learn from HIV? Lancet Oncol 2003:4:438-45.

15 Stebbing J, Marvin V, Bower M. The evidence-based treatment of AIDS-related non-Hodgkin's lymphoma. Cancer Treat Rev 2004;30:249-53.

16 Stebbing J, Gazzard B, Mandalia S, et al. Antiretroviral treatment regimens and immune parameters in the prevention of systemic AIDS-related nonHodgkin's lymphoma. J Clin Oncol 2004;22:2177-83. 